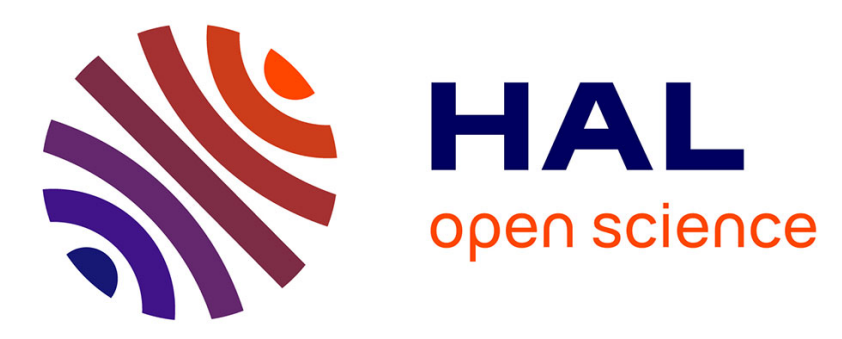

\title{
A Novel Configuration of a Microstrip Microwave Wideband Power Amplifier for Wireless Application
}

Amine Rachakh, Larbi El Abdellaoui, Jamal Zbitou, Ahmed Errkik, Abdelali Tajmouati, Mohamed Latrach

\section{- To cite this version:}

Amine Rachakh, Larbi El Abdellaoui, Jamal Zbitou, Ahmed Errkik, Abdelali Tajmouati, et al.. A Novel Configuration of a Microstrip Microwave Wideband Power Amplifier for Wireless Application. Telkomnika (Telecommunication, Computing, Electronics and Control), 2018, 16 (1), pp.224-231. 10.12928/telkomnika.v16i1.7369 . hal-01940661

\section{HAL Id: hal-01940661 https://hal.science/hal-01940661}

Submitted on 17 Jul 2019

HAL is a multi-disciplinary open access archive for the deposit and dissemination of scientific research documents, whether they are published or not. The documents may come from teaching and research institutions in France or abroad, or from public or private research centers.
L'archive ouverte pluridisciplinaire $\mathbf{H A L}$, est destinée au dépôt et à la diffusion de documents scientifiques de niveau recherche, publiés ou non, émanant des établissements d'enseignement et de recherche français ou étrangers, des laboratoires publics ou privés. 
TELKOMNIKA, Vol.16, No.1, February 2018, pp. 224 231

ISSN: 1693-6930, accredited A by DIKTI, Decree No: 58/DIKTI/Kep/2013

DOI:10.12928/TELKOMNIKA.v16i1.7369

\title{
A Novel Configuration of a Microstrip Microwave Wideband Power Amplifier for Wireless Application
}

\author{
Amine Rachakh ${ }^{{ }^{*}}$, El Abdellaoui Larbi ${ }^{2}$, Zbitou Jamal ${ }^{3}$, Ahmed Errkik ${ }^{4}$, Abdelali \\ Tajmouati $^{5}$, Latrach Mohamed ${ }^{6}$ \\ $1,2,3,4,5$ LMEET, FST of Settat Hassan 1st University Settat, Morocco. \\ University Complex, Casablanca Road, Km 3.5, B.P: 577 Settat, Morocco. \\ ${ }^{6}$ Microwave group ESEO Angers France, 10 Bd Jeanneteau - CS 9071749107 ANGERS CEDEX 2. \\ ${ }^{*}$ Corresponding author, e-mail: rachakh.amine1@gmail.com
}

\begin{abstract}
$R F /$ microwave power amplifier $(P A)$ is one of the components that has a large effect on the overall performance of communication system especially in transmitter system and their design is decided by the parameters of transistor selected. This letter presents a new concept of a wide-band microwave amplifier using scattering parameters that is often used in the radio frequency communication systemas an application of the active integrated antenna[1 - 2]. This power amplifier operates from $1.75 \mathrm{GHz}$ to $2.15 \mathrm{GHz}$ frequency and it is based on AT-41410 NPN transistor that has a high transition frequency of 10GHz. The proposed Single Stage PA is designed by microstrip technology and simulated with Advanced Design System (ADS) software. The simulation results indicate good performances; the small power gain (S21) is changed between 11.8 and 10dB. For the input reflection coefficient (S11) is varied between -11 and 22.5dB. Regarding the output reflection coefficient (S22) is varied between -13.1 and -18.7dB over the wide frequency band of $1.75-2.15 \mathrm{GHz}$ and stability without oscillating over a wide range of frequencies.
\end{abstract}

Keywords: wideband power amplifier, microstrip technology, input matching, output matching, bipolar junction transistors (BJTs), advanced design system (ADS)

Copyright $\odot 2018$ Universitas Ahmad Dahlan. All rights reserved.

\section{Introduction}

As wireless communication technology advances, Microwave power amplifier becomes an important study issue, because it is the key component of wireless communication transmitter [3]. Communication quality and power consumption of the communication device depend on performance of the amplifier. Although power amplifiers are parts of the transmitters only, their design should take into consideration the general features of the full communications system [4]. One of the key design goals for the power amplifier is a good impedance matching, together with a wide bandwidth, a sufficiently large power gain range and a low power consumption.

The wideband and the narrow band microwaves power amplifiers are very utilized in the detection and the communication systems (radio communication, spatial telecommunication, control system, radar detection ...) [5]. The matching networks of these power amplifiers are designed through distributed elements (transmission lines) or to basis of localized elements (capacitors and inductances) orassociation of both techniques [6,12]. The employ of the matching networks by the distributed elements or localized elements depend on the operation frequency. Indeed, for low frequencies the localized elements are mostly used, and for the more high frequencies the distributed elements are widely used, this for technological constraints and the economic [9].

In this work, we present a new design of a wide-band microwave power amplifier using the transistor AT-41410 that of type Si-BJT (Bipolar Junction Transistor). This power amplifier utilizes microstrip transmission lines matching to match the input and output at $50 \mathrm{Ohm}$. In what follows, we present the design of a wide-band microwave power amplifier using s-parameters, where we study the microwave amplifier in the DC mode and next we simulate the amplifier using ADS (Advanced Design System) software. In addition, we show the performances of the microwave wide-band amplifier. Finally, we conclude. 


\section{Design of a Wide-Band Microwave Power Amplifier Using S-Parameters}

The block diagram of the microwave PA is presented in Figure 1. The impedance matching network at the base and collector terminals of the BJT transistor is designed to match the wide bandwidth signal with a $50 \Omega$ system impedance. The bias network used to determine the PA performance over tension as well as RF drive.

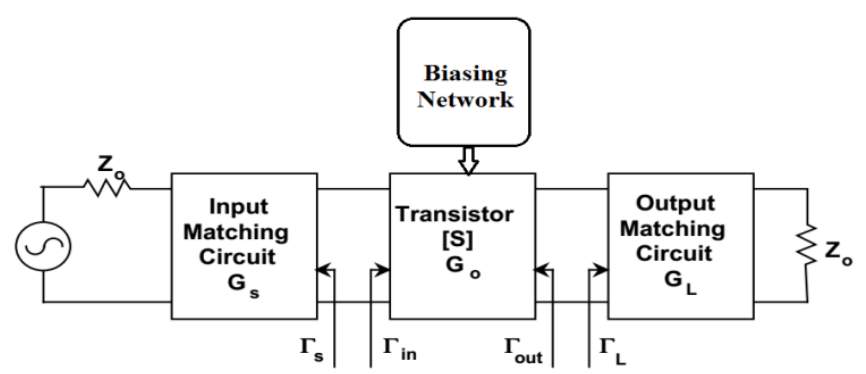

Figure 1. Basic microwave power amplifier schematic

In order to obtain good performancesfor a microwave power amplifier, the input and the output impedances of the device must be matched. Among various types of matching networks (MN) we can find:

a. Quarter-wave transformers.

b. Multi-section transformers.

c. Lumped Elements.

d. Microstrip line \& single (or double) stub.

Microstrip amplifier are widely used for wireless applications as: military purposes, satellite communication, GPS, missile systems, mobile etc. This kind of microwave amplifier presents some advantages:

a. It has a very low fabrication cost.

b. Ease of manufacturing.

c. Easy in integration with microwave passive and active circuits.

According to idea noticed above as illustrated in Figure 1 we propose a wide-band microwave PA with a microstrip technology and by using scattering parameters. This PA works from $1.75 \mathrm{GHz}$ to $2.15 \mathrm{GHz}$ frequency, we can increase or decrease the frequency band by adding or removing the number of stubs in the input or the output side. Figure 2 gives the proposed schematic of the overall microstrip microwave power amplifier.

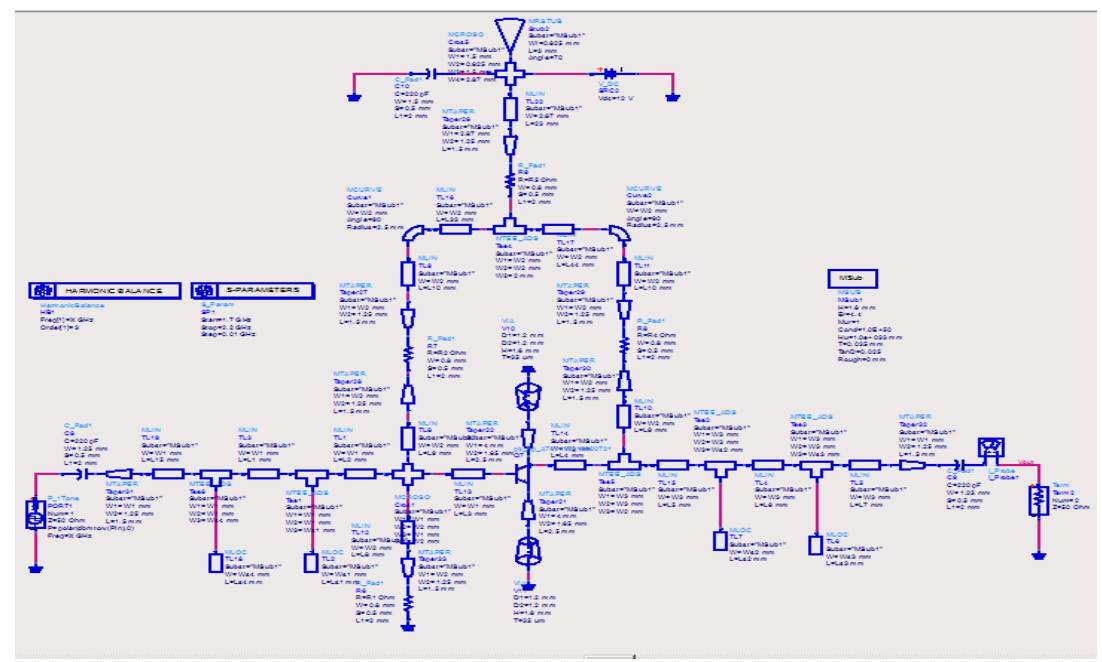

Figure 2. Wide-band microwave power amplifier circuit 


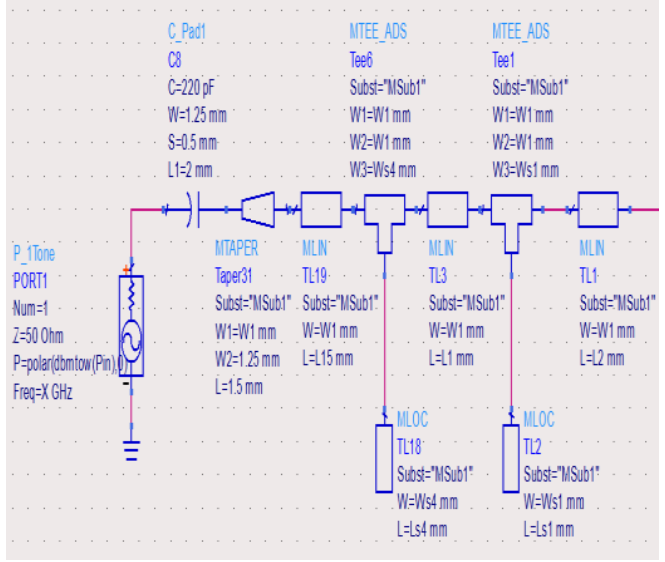

Figure 2(a). Input matching network circuit

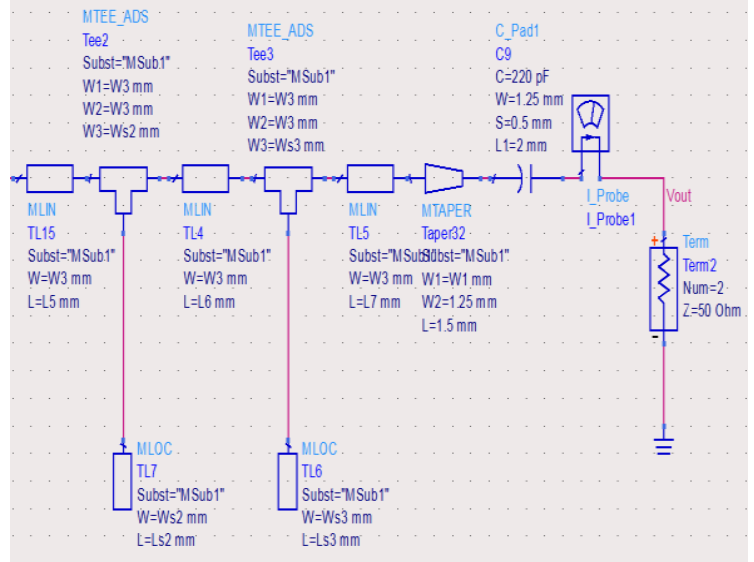

Figure 2(b). Output matching network circuit

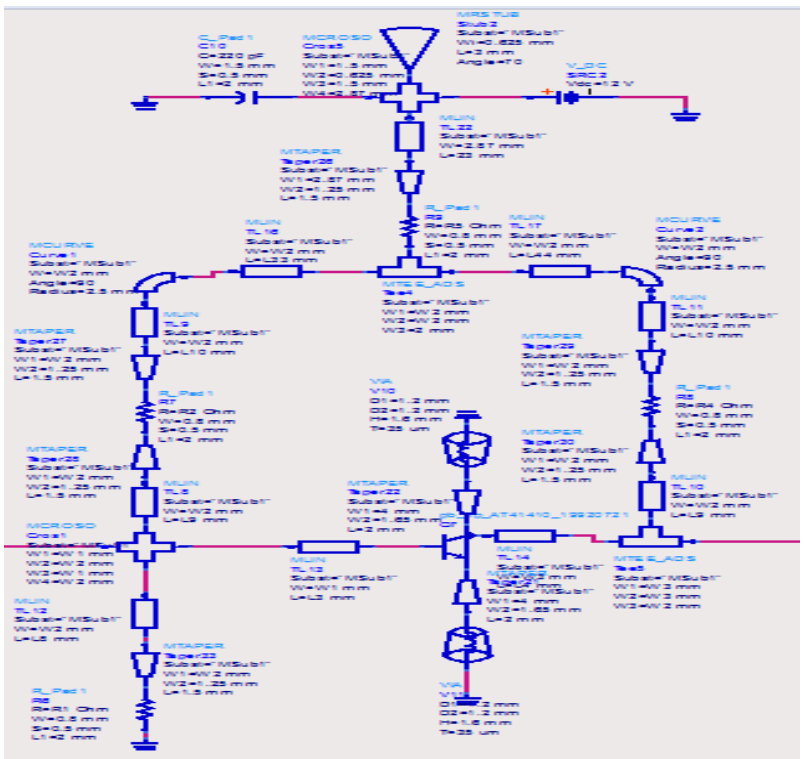

Figure 2(c). Biasing circuit

The designs of PA, there are various common aims. These contain reducing the reflections of the PA, producing large power gain with high output power and assuring stable condition. Are all-important considerations [13]. In order to make a PA, the selection of active device is critical. This is one of the most influential steps in designing a PA. Different types of active devices are used for power amplifier applications. In accordance with specifications, adequate transistor should be chosen for PA owing to its high gain and low cost [14]. The numbers of transistors are finite at the frequency of applications. In this work, AT-41410 is chosen.

\section{DC-mode of Microwave Amplifier}

To study the functioning of AT-41410 microwave transistor in DC mode, we raised the characteristics network $I C=f(V C E, I B)$ through the ADS software. Figure 3 shows this characteristic network of AT-41410. For biasing the transistor in the linear zone of its characteristic, we adopted the DC equivalent schematic of microwave power amplifier that is shown in the Figure 4 . We determine the resistances of biasing $R_{1}, R_{2}, R_{3}$ and $R_{4}$ allowing to obtain the biasing point; $I_{C}=6 m A, V_{C E}=3 V$ and $I_{B}=60 \mu A$ from a bias source $V_{d c}$ of $12 \mathrm{~V}$. 


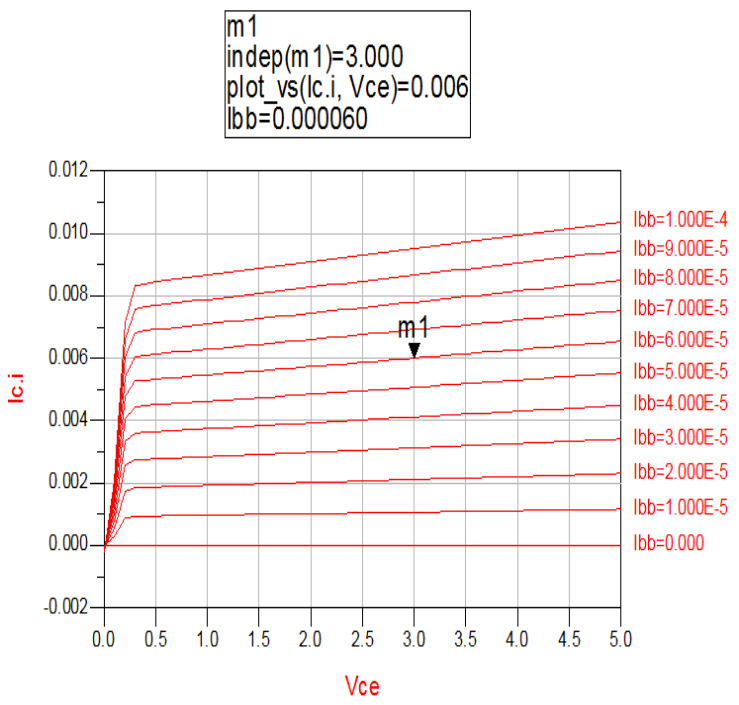

Figure 3. The Characteristics Network $I_{C}=f$ $\left(\mathrm{V}_{\mathrm{CE}}, \mathrm{I}_{\mathrm{B}}\right)$ of Transistor AT-41410

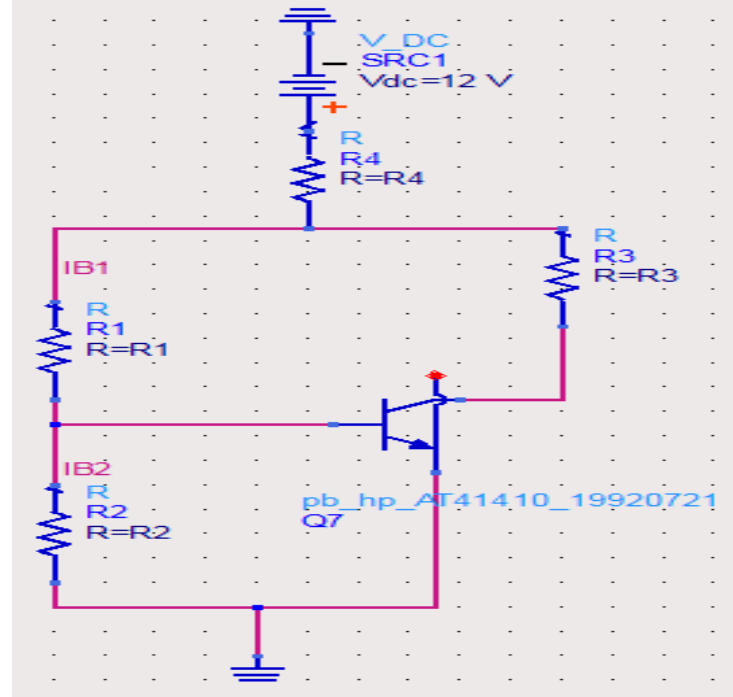

Figure 4. DC Equivalent Schematic of Microwave Power Amplifier

In order to determine the values of the biasing resistances, we should have four equations; two equations are given from Kirchhoff's loop rule, whilst the two others from the two following conditions: $I_{B 1}=9 I_{B}$ and we want a voltage fall to boundary-marks of $R_{5}$ equals to $3 \mathrm{~V}$. From the Figure 4 , the resistance $R_{1}$ can be calculated as:

$$
R_{1}=\frac{V_{C E}-V_{B E}+R_{3} I_{C}}{I_{B 2}}
$$

The value of resistance $R_{2}$ is calculated by Equation (2):

$$
R_{2}=\frac{V_{B E}}{I_{B 2}}
$$

The value of resistance $R_{3}$ is determined by Equation (3):

$$
R_{3}=\frac{V_{C C}-V_{C E}-3.5}{I_{C}}
$$

The value of the resistance $R_{4}$ can be expressed as:

$$
R_{4}=\frac{3.5}{10 I_{B}+I_{C}}
$$

The polarization resistances are shown in the Table 1.

Table 1. Values of Polarization Resistors of the Proposed Power Amplifier

\begin{tabular}{cc}
\hline resistors & Values $(\Omega)$ \\
\hline R1 & 13000 \\
R2 & 1500 \\
R3 & 820 \\
R4 & 470 \\
\hline
\end{tabular}




\section{Simulation Results and Discussion}

The proposed wide-band power amplifier was characterized by small and large-signal simulations. The large-signal simulation were obtained by Harmonic Balanced simulator for achieve variation of output power with corresponding input power. Where scattering parameters simulations were utilized to get a small signal (Small-Signal Gain, Return loss ...).

Both small and large signal simulations have been executed by the advanced Design System (ADS) software.

The simulation S-parameter result illustrated in figures below. As depicted figure 4 presents the variation of the power gain S21 and the unilateral transmission (S12) between $1.75 \mathrm{GHz}$ and $2.15 \mathrm{GHz}$. it can be observed that this power gain changes between $11.7 \mathrm{~dB}$ and $10 \mathrm{~dB}$. Thus, these values indicate a good amplification of the microwave PA over a wideband and for the unilateral transmission; we notice that this parameter changes between -18.4 and 19.3dB. These values are feeble. Consequently, the reflection of the power from load to source is without effect.

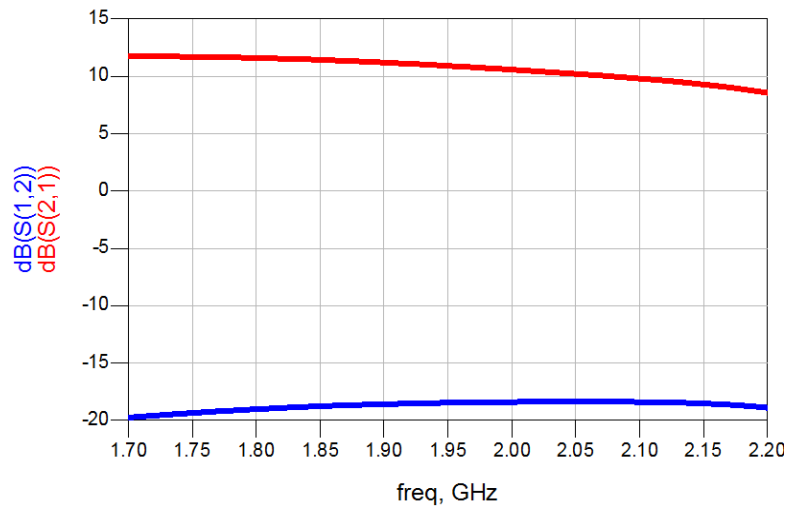

Figure 4. Plot of the power gain (S21) \& the reverse transmission (S12) versus frequency

Figure 5 illustrates the variation plot of the input return loss (S11) in the frequency band 1.75GHz-2.15GHz. We observed that the parameter $\mathrm{S} 11$ varied between $-11 \mathrm{~dB}$ and $-22.5 \mathrm{~dB}$. Thus, these values indicate a good input matching of the microwave PA over a wide-band and the reflection of the signal from the PA input to the source is low. The output matching can be determined by simulating the return loss (S22). Figure 6 shows the plot of this parameter. It can be observed that the output matching is good since S22 changes between $-13.1 \mathrm{~dB}$ and $18.7 \mathrm{~dB}$. So; the reflection of the signal from the PA output to the load is rather feeble.

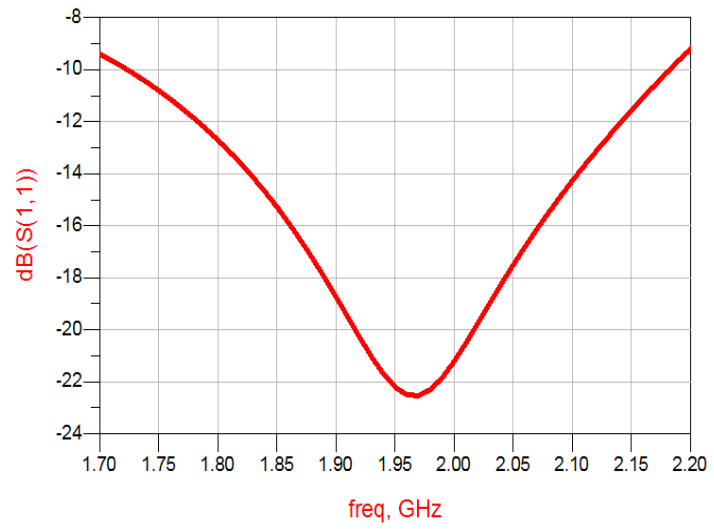

Figure 5. Plot of the input reflection coefficient (S11) versus frequency

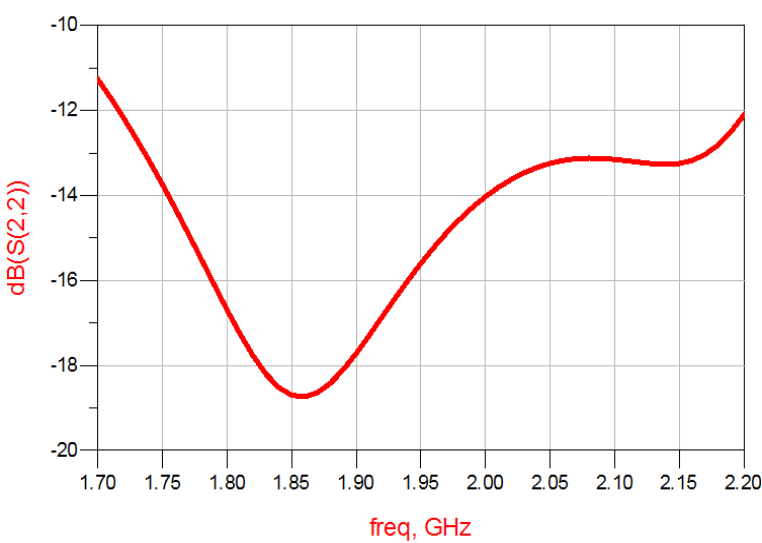

Figure 6. Plot of the output reflection coefficient (S22) versus frequency 
The PA circuits must be stable in operating frequency band. That is primary to $\mathrm{RF} /$ microwave circuits, due to $\mathrm{RF} /$ microwave circuits would generate oscillation in someone operating frequency or some terminal conditions. These oscillations can raise the power gain of PA significantly and the active device could be damaged. thus, the important step to designing the power amplifier is to find the stability of the PA and combine the circuit components to ensure the stability in operating frequency band [15]. The PA can be considered as a two-port network that can be modelled by $S$ parameter. thus, the absolute stability condition of PA can be determined by the Equations (5), (6) and (7) [16] and [17]:

$$
\begin{aligned}
& k=\frac{1-\left|\mathrm{S}_{11}\right|^{2}-\left|\mathrm{S}_{22}\right|^{2}+|\Delta|^{2}}{2\left|\mathrm{~S}_{12} \mathrm{~S}_{21}\right|}>1 \\
& B_{1}=1+\left|\mathrm{S}_{11}\right|^{2}-\left|\mathrm{S}_{22}\right|^{2}-|\Delta|^{2}>0 \\
& |\Delta|=\left|\mathrm{S}_{11} \mathrm{~S}_{22}-\mathrm{S}_{12} \mathrm{~S}_{21}\right|
\end{aligned}
$$

Where: $\mathrm{k}$ is the Rolett factor.

B1 is the Stability measure.

In order to satisfy the unconditional stability and assure an input/output matching at $50 \mathrm{Ohm}$ of microwave PA, a Taper line was added in series to improve the stability at the emitter path. This mean is easy to realize and the effect is better. Figure 7 represents the plots of the stability measure $B 1$ and the stability factor $K$ versus frequency. From Figure 7 , it can be observed that $\mathrm{B} 1>0$ and $\mathrm{K}>1$ over operating band $1.75 \mathrm{GHz}-2.15 \mathrm{GHz}$. Thus, the conditions for unconditional stability are validated on the working frequency band. Therefore, there is no risk to get oscillations. We simulated the scattering parameters (Sij) to show the good functioning of the microwave PA in the frequency range 1.70GHz-2.20GHz. As shown in Figure 8, this study was conducted at $2 \mathrm{GHz}$ for power input range from -30 to $30 \mathrm{dBm}$. The PA exhibits a saturated output power of $8 \mathrm{dBm}$ at $1 \mathrm{~dB}$ compression point.

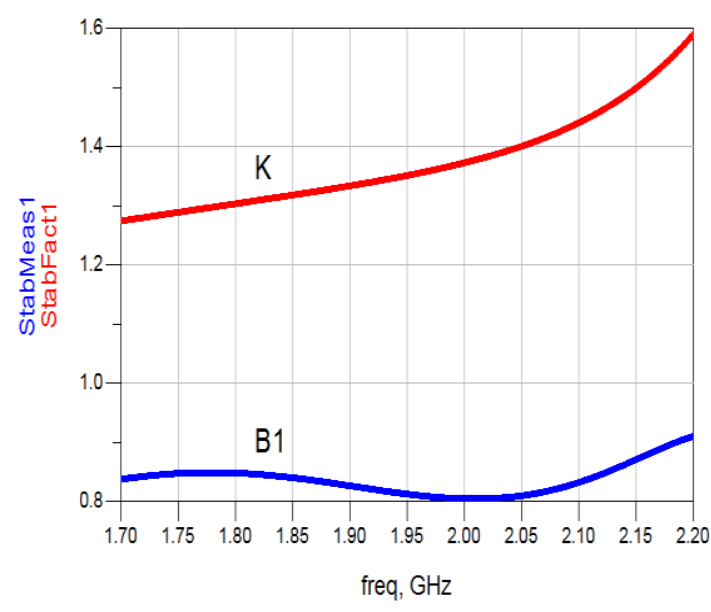

Figure 7. Plot of the stability measure B1 and the stability factor $K$ versus frequency

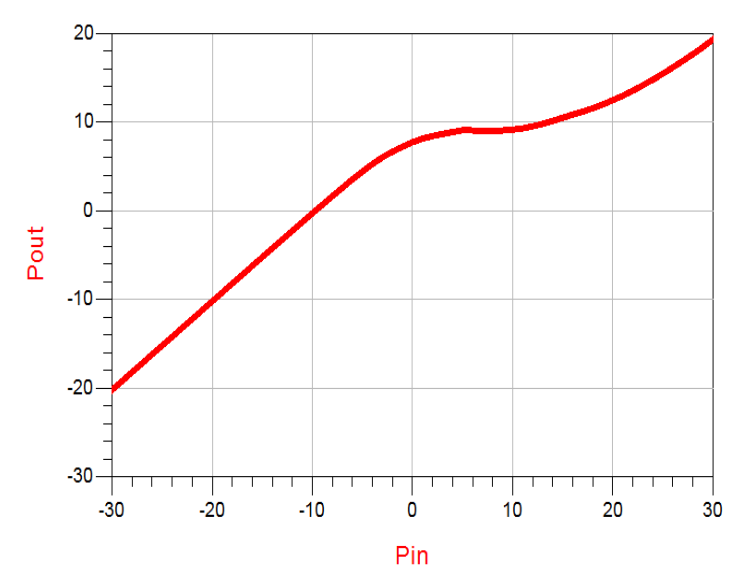

Figure 8. Input power versus output power for $2 \mathrm{GHz}$

\section{Layout for Wideband Power Amplifier Circuit}

The amplifier is printed on an FR4 substrate with a relative permittivity of 4.4 ,a thickness of $1.6 \mathrm{~mm}$, a metallization thickness $\mathrm{t}=0.035 \mathrm{~mm}$ and a tangential loss of 0.025 . The 
proposed wide-band amplifier has an overall size of about $66 \times 65.3 \mathrm{~mm}^{2}$. Figure 9 shows the Layout for the proposed PA.

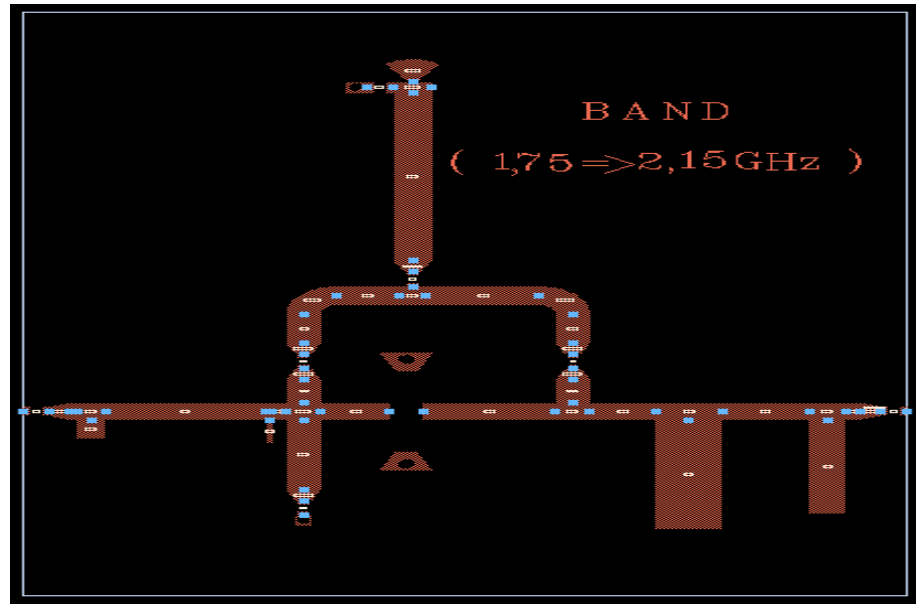

Figure 9. Layout of proposed wide-band amplifier

Finally, we compared the proposed wideband power amplifier with other recently published articles on state-of-the-art of power amplifiers, the results are shown in Table 2. It can be remarked that the proposed wideband amplifier has considerably a power gain and reflection coefficients over a wider bandwidth than other PAs, which verifies the results show excellent performance of our design approach compared to the reported works.

Table 2. Comparision The Proposed Amplifier With other Recently Amplifiers

\begin{tabular}{cccc}
\hline Parameter & {$[18]$} & {$[19]$} & $\begin{array}{c}\text { The Proposed } \\
\text { Amplifier }\end{array}$ \\
\hline Process & CMOS & CMOS & BJTs \\
Frequency (GHz) & 1.65 to 2.00 & 1.70 to 3.10 & 1.75 to 2.15 \\
Power Gain (dB) & $5.1 \pm 5$ & 9.8 & $11 \pm 0.5$ \\
Input Return Loss (dB) & -21 & -7 & -22 \\
Output Return Loss (dB) & -8 & - & -18 \\
\hline
\end{tabular}

\section{Conclusion}

In this paper, the proposed wide-band PA working from $1.75 \mathrm{GHz}$ to $2.15 \mathrm{GHz}$ had been designed. A microstrip technology has been utilized in the PA design in order to meet the design specification over the wide frequency ranges. The biasing circuits and matching impedance are also accurately designed so that the design specifications are met with lowest components. Optimization and tuning of the circuit are very important to confirm that the amplifier yields the excellent performance. The simulation results of the final Single stage PA illustrate that the power gain (S21) is above $11 \mathrm{~dB}$. The power gain was almost flat over the full band, the unilateral transmission (S12) less than $-19 \mathrm{~dB}$, the input return loss $\mathrm{S} 11$ is between 11 and $-22 \mathrm{~dB}$, while the output return loss $\mathrm{S} 22$ ranges is between $-13 \mathrm{~dB}$ and $-18 \mathrm{~dB}$. The proposed wide-band power amplifier has an average saturated output power of $8 \mathrm{dBm}$ at $1 \mathrm{~dB}$ compression point and stability without oscillating in its required frequency band.

\section{Acknowledgment}

I would like to express my deep gratitude to Mr. Mohamed Latrach Professor in ESEO, engineering institute in Angers, France, for allowing us to use electromagnetic solvers available in his laboratory. 


\section{References}

[1] AF Morabito, AR Laganà, G Sorbello, T Isernia. Mask-Constrained Power Synthesis of Maximally Sparse Linear Arrays througha Compressive-Sensing-Driven Strategy. Journal of Electromagnetic Waves and Applications. 2015; 29(10): 1384-1396.

[2] AF Morabito, AR Lagana, T Isernia. Isophoric Array Antennas with a Low Number of Control Points: A 'Size Tapered' Solution. Progressin Electromagnetics Research Letters. 2013; 36: 121131.

[3] Tsaraklimanis A, Karagianni E. Low Noise Amplifier Design for Digital Television Applications. Journal of Electromagnetic Analysis and Applications. 2011; 03(07): 291-296.

[4] Munir A, Ranum B. Single Stage RF Amplifier with High Gain for 2.4GHz Receiver Front-Ends. TELKOMNIKA (Telecommunication Computing Electronics and Control). 2014; 12(3): 711.

[5] Medley M. Microwave and RF circuits. Boston [u.a.]: Artech House; 1993.

[6] Niclas K, Wilser W, Kritzer T, Pereira R. On Theory and Performance of Solid-State Microwave Distributed Amplifiers. IEEE Transactions on Microwave Theory and Techniques. 1983; 31(6): 447456.

[7] M Bacha, L Hadj Abderrahmane. Design of Broadband Microwave Amplifier for Telecommunication Applications. The 14th IASTED International conference on Applied Simulation and Modelling. Benalmadèna, Spain. 2005.

[8] Matthaei G, Young L, Jones E. Microwave filters, impedance-matching networks, and coupling structures. Norwood: Artech House. 1985.

[9] Tri T Ha. Solid State Microwave Amplifier Design. A Wiley Interscience Publication. 1981.

[10] Riblet G. Broad-band internally and externally matched lumped element symmetrical 5-ports. IEEE Transactions on Circuits and Systems. 1985; 32(12): 1209-1213.

[11] R Beltran, FH Raab. Lumped-Element Output Networks For High-Efficiency Power Amplifiers. IEEE MTT-S International Microwave Symposium, Anaheim, CA. 2010: 324 327.

[12] Martinez Mendoza M, Wentzel A, Alvarez Melcon A, Heinrich W. Advanced lumped-element filters for digital microwave power amplifiers. International Journal of Microwave and Wireless Technologies. 2015; 7(05): 589-596.

[13] Li Z, Guo B, Wei Z, Liu S, Cheng N, Wang J et al. A gain-flatness optimization solution for feedback technology of wideband low noise amplifiers. Journal of Zhejiang University SCIENCE C. 2011; 12(7): 608-613.

[14] Venkat Ramana. Aitha, Mohammad Kawsar Imam. Low Noise Amplifier for Radio Telescope at 1.42 GHz. Computer and Electrical Engineering, Halmstad University, Sweden, IDE0747. 2007: 29.

[15] L. Samoska et al. On The Stability Of Millimeter-Wave Power Amplifiers. IEEE MTT-S International Microwave Symposium Digest (Cat. No.02CH37278), Seattle, WA, USA, 2002; 1: 429-432.

[16] Chang K, Bahl I, Nair V. RF and microwave circuit and component design for wireless systems. New York: Wiley. 2002.

[17] Vendelin G. Design of amplifiers and oscillators by the S-parameter method. New York: Wiley. 1982; 200.

[18] H Aniktar, H Sjoland, JH Mikkelsen, T Larsen, A Class-AB 1.65GHz-2GHz Broadband CMOS Medium Power Amplifier. NORCHIP; 2005: 269-272.

[19] D Kalim, D Erguvan, R Negra, A $1.7 \mathrm{GHz}$-to-3.1 GHz Fully integrated broadband Class-E Power Amplifier in $90 \mathrm{~nm}$ CMOS. 6th Conference on Ph.D. Research in Microelectronics \& Electronics. Berlin. 2010: 1-4. 